\title{
Volume Flow Characterization of PWM-Controlled Fast-Switching Pneumatic Valves
}

\author{
Miha Pipan* - Niko Herakovič \\ University of Ljubljana, Faculty of Mechanical Engineering, Slovenia
}

In this paper we present results of an experimental analysis of the dependence of volume flow on pulse width modulation (PWM) control signal through a fast-switching pneumatic valve. The main goal of this study is to determine how the PWM frequency and duty cycle (pulse width) influence the volume flow and if there is a correlation between them. The highest PWM signal frequencies that can control the tested fastswitching valve were used. This way we minimised the influence of pressure pulsation that can make a pneumatic system, pressure regulator and flow sensor unstable at lower frequencies. The aim was also to determine if pressure difference and PWM frequency have any influence on the shortest pulse needed to open the valve. The volume flow was measured with a state-of-the-art mass flow sensor that can calculate average volume flow and isn't influenced by high-frequency pressure pulsation. We also made temperature measurement in a valve solenoid and pressure chamber during an 8-hour excitation with a PWM signal.

Keywords: fast switching valves, PWM, flow characteristics, pulse width

Highlights

- $\quad$ The minimum width of PWM pulse needed for a fast-switching valve to open increases with the increase of pressure difference.

- $\quad$ The correlation between pulse width and average volume flow of the valve is highly nonlinear with initial steep response at lower pressure differences.

- Maximum PWM frequency used to control the fast-switching valve is limited by response time of the valve and also by the maximum number of valve cycles.

- Experimental results show that digital PWM control technique can be used effectively with fast-switching valves.

\section{O INTRODUCTION}

Pneumatic actuators are widely used in industry and are generally used for two position controls. When the continuous position control is required, pneumatic servo or proportional valves are used. Pneumatic servo valves are expensive and proportional valves do not have the fastest response time due to the spool dead band. The alternative is to use fast-switching valves with digital control techniques to achieve linear flow control characteristics with the fastest possible response. The implementation of fast switching valves for position control using digital control techniques has been in development for the last 10 years. The main reason that enables us to use pulse width modulation (PWM) control method is newly developed valves with response times shorter than a few milliseconds. PWM signal is [1] a sequence of short electrical pulses that open a valve for a fraction of time. After each pulse another pulse with the same or different pulse width follows. The change of pulse width achieves different air pressure bursts. The change in number and duration of these pressure bursts modifies the average flow through the fastswitching valve. In this paper we wanted to analyse the influence of different PWM control signals on the average flow characteristics of the fastest switching pneumatic valve that is currently available in the market.

The results will be used for the development of a control algorithm for fast-switching valves that control contraction of pneumatic artificial muscles. This has been done before with switching valves that have shorter switching time of $2 \mathrm{~ms}$ [2], $20 \mathrm{~ms}$ [3], 2 ms [4] and without taking into account the change of minimum pulse and nonlinear relation between pulse width and air flow. If flow pulsation is in high frequency domain it can be defined as average flow since a pneumatic muscle with a large enough volume acts as a low-pass filter similar to DC motors controlled via PWM [5]. The natural frequency of muscle changes depending on internal pressure and contraction but based on our and other research [6] the natural frequency has values between $9 \mathrm{~Hz}$ to $42 \mathrm{~Hz}$. With the use of high PWM frequency we excitate the muscle with pulsation that is in over-critical frequency domain and does not make the pneumatic muscle unstable.

Many researchers used PWM control techniques to drive pneumatic switching valves with good results. The PWM signal frequencies $f_{P W M}[\mathrm{~Hz}]$ used depend on the valve response time and were between 10 and 
$50 \mathrm{~Hz}$ [7], $100 \mathrm{~Hz}$ [8], up to $50 \mathrm{~Hz}$ [9], $100 \mathrm{~Hz}$ [10], $50 \mathrm{~Hz}$ [11] and 20 to $60 \mathrm{~Hz}$ [12]. Efforts were made to develop electro-pneumatic valve models based on the electrical and pneumatic parts modelling and to use these models in a PWM-driven pneumatic system [8], [9] and [13]. The relationship between the pulse width and the fluid flow was always defined to be linear, and the minimum PWM pulse was used in only one paper, [7] and [14]. The relationship between electrical, magnetic and mechanical components can be modelled with lumped parameter valve model to simulate switching times and to compare results with obtained valve experimental data [15]. An interesting finding was that the closing time of the valve is not only a function of pressure difference but also of magnetic hysteresis, magnet supply voltage and Eddy current. In the latest research, the relationship between the pressure difference and the solenoid current in pneumatic switching valves [16] is considered.

But there were no experimental analyses performed or models developed that would directly describe the influence of the valve pressure difference on the minimum pulse width. The standard equation of the fluid flow through a pneumatic valve is defined in the ISO 6358 standard, Eq. (1) [17], and is used in this form in almost all mathematical models of pneumatic switching valves.

$$
\dot{V}_{a}=\left\{\begin{array}{c}
P_{1} C \frac{T_{0}}{T_{1}} \sqrt{1-\left(\frac{\frac{P_{2}}{P_{1}}-b}{1-b}\right)^{2}} \text { for } \frac{P_{2}}{P_{1}}>b \\
P_{1} C \frac{T_{0}}{T_{1}} \text { for } \frac{P_{2}}{P_{1}} \leq b
\end{array},\right.
$$

where $\dot{V}_{a}$ represents the volume flow $\left[\mathrm{m}^{3} / \mathrm{s}\right], P_{1}$ the absolute inlet pressure $[\mathrm{Pa}], P_{2}$ the absolute outlet pressure $[\mathrm{Pa}], C$ the acoustic conductivity $\left[\mathrm{m}^{3} /(\mathrm{s} \cdot \mathrm{Pa})\right], T_{0}$ the ambient temperature $[\mathrm{K}], T_{1}$ the temperature of inlet air $[\mathrm{K}]$, and $\mathrm{b}$ the critical ratio. The characteristics of the tested valve MHJ10-MF are as follows: $C=2.6167 \times 10^{-9} \mathrm{~m}^{3} /(\mathrm{s} \cdot \mathrm{Pa})$ and $b=0.433$. But this model does not describe what happens when the valve is controlled via the PWM signal and when the valve is in constant transit states between being opened and closed. Therefore, this model can only be used when the valve is fully opened. To accurately simulate air flow through a valve in transit state and single switching (probably multiple Eddy flows), a combination of Lumped Parameter Valve Model [15] for determining the spool position as a function of time for a single actuation with additional field simulation for flow rate calculation [18] is needed. Simulation model based on this will be developed in future work and will be compared with experimental data presented in this paper.

Experimental data will also enable verification of a new valve model developed in the future based on a similar simulation model [19], the development of control algorithm for position and force control [20], failure analysis [21] and deformation analysis of controlled pneumatic actuator [22].

In this paper, we present the results of an extensive analysis of the behaviour of fast- switching valves when using different PWM signals and the way the average flow changes. In the first part of the paper the executed test plan with all PWM frequencies, pulse widths and pressure differences is described. Later the experimental setup with all the components is presented. In the last part of the paper results are presented, compared and discussed.

\section{METHODS}

The Experimental analysis is performed under various pressure differences $\Delta P$ [bar], three different frequencies and multiple pulse widths. The tested valve is MHJ10-LF. This valve has an open time $t_{o n}$ and close time $t_{\text {off }}$ less than $1 \mathrm{~ms}$. The maximum usable frequency is therefore $500 \mathrm{~Hz}$ if it takes $1 \mathrm{~ms}$ to open the valve and $1 \mathrm{~ms}$ to close the valve. But at this frequency we can only open and close the valve without having any influence on the duration in which the valve is opened. Therefore, we chose to test frequencies between $200 \mathrm{~Hz}$ and $300 \mathrm{~Hz}$. With these frequencies we were able to control the duration in which the valve is opened and closed while staying as far from the natural frequency of the pneumatic systems as possible. At lower frequencies the longlasting pressure bursts can cause problems [23] and the controlled pneumatic systems can become unstable since we come closer to pneumatic components' natural frequencies that are between $9 \mathrm{~Hz}$ to $42 \mathrm{~Hz}$ [6].

The pulse width can be measured in time ( $t_{\text {pulse }}$ $[\mathrm{ms}])$ or as the percentage of the PWM period width $\left(t_{\text {pulse\% }}[\%]\right)$ called 'duty cycle'. In Fig. 1 the valve input control PWM signal with the amplitude of $24 \mathrm{~V}$, frequency $f_{P W M}=250 \mathrm{~Hz}$ and $25 \%$ duty cycles (pulse widths) and measured average volume flow is shown.

The average flow measurement was taken when measured flow stabilised after 10 seconds of continuous valve control with PWM for single frequency and duty cycles. The 10 seconds are needed because of slow response of the flow sensor. 

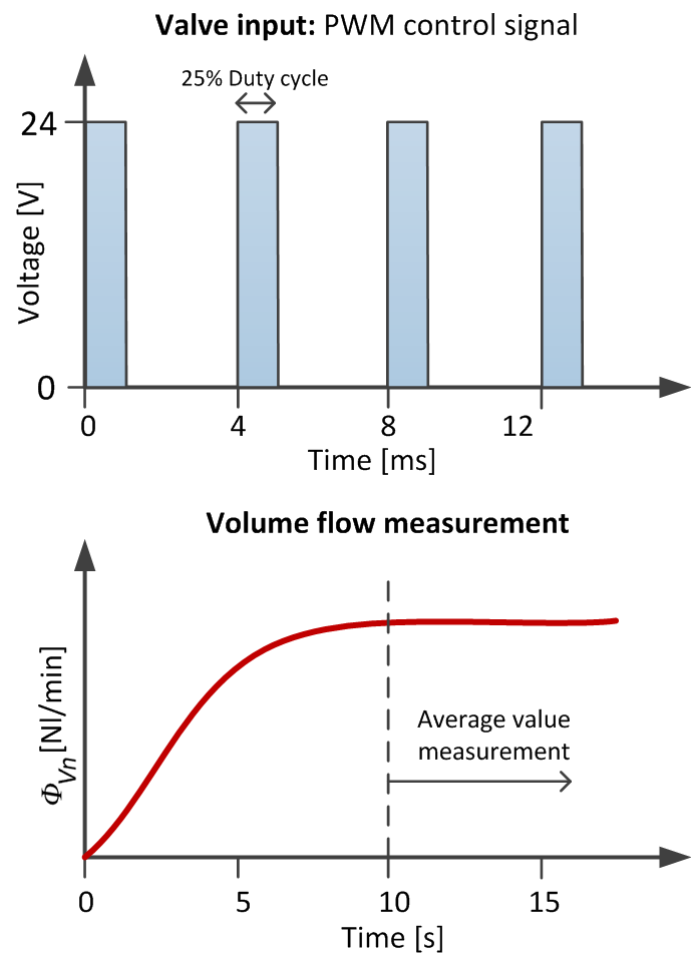

Fig. 1. Valve input PWM signal and average volume flow measurement

Different pulse widths were chosen to measure the influence on the average volume flow. The pulse width was changed in steps of $1 \%$ for the range of $0 \%$ to $10 \%$ and with steps of $10 \%$ from $10 \%$ to $100 \%$ of pulse width (duty cycle). Smaller steps of pulses between $0 \%$ and $10 \%$ are needed to accurately measure how the average volume flow changes when the valve is just beginning to open. The minimum pulse width $t_{\min \%}$ [\%] when the air mass flow sensor detects the flow is set with the accuracy of $0.1 \%$. Maximum pulse that still has an influence on volume flow $t_{\max \%}$ is set with the same accuracy. The executed experimental analysis plan with all used frequencies, pressure differences and pulse widths is shown in Table 1.

Table 1. Fast switching valve PWM test plan

\begin{tabular}{cccccc}
\hline $\begin{array}{c}f_{P W M} \\
{[\mathrm{~Hz}]}\end{array}$ & $\begin{array}{c}\Delta P \\
{[\mathrm{bar}]}\end{array}$ & $\begin{array}{c}t_{\text {pulse\% }} \\
0 \text { to } 10[\%]\end{array}$ & $\begin{array}{c}t_{\text {pulse } \%} \\
10 \text { to } 90[\%]\end{array}$ & $\begin{array}{c}t_{\min \%} \\
{[\%]}\end{array}$ & $\begin{array}{c}t_{\max \%} \\
{[\%]}\end{array}$ \\
\hline & 0.10 & & & & \\
& 0.30 & & & & \\
& 0.50 & & & manual & manual \\
200 & 1.00 & & & with & with \\
250 & 2.00 & $1 \%$ step & $10 \%$ step & $0.1 \%$ & $0.1 \%$ \\
300 & 3.00 & & & step & step \\
& 4.00 & & & & \\
& 5.00 & & & & \\
\hline
\end{tabular}

Experimental analysis was performed for every frequency using the following steps:

1. Set the PWM frequency, $f_{P W M}$.

2. Set the desired pressure difference, $\Delta P$, with the pressure regulator and fine tune it using the pressure sensor for reference.

3. Increase the PWM pulse, $t_{p u l s e} \%$, until the flow is detected to find $t_{\min \%}$.

4. Increase the $t_{p u l s e} \%$ from $0 \%$ to $10 \%$ in $1 \%$ steps and save the measured flow.

5. Increase the $t_{\text {pulse }}$ from $10 \%$ to $90 \%$ in $10 \%$ steps and save the measured flow.

6. Find the maximum pulse width, $t_{\max \%}$ which still has an effect on the flow.

7. Set the new pressure difference, $\Delta P$, and repeat steps 3 to 7.

8. Repeat steps from 1 to 7 for all frequencies, $f_{P W M}=200 \mathrm{~Hz}, 250 \mathrm{~Hz}$ and $300 \mathrm{~Hz}$.

\section{EXPERIMENTAL}

The dependence of the fluid flow characteristics on the pulse width and frequency needs to be accurately measured. Fig. 2 shows the experimental setup scheme and all electrical and pneumatic components used where: A is air preparation, B is pressure regulator, $\mathrm{C}$ is pressure sensor, $\mathrm{D}$ is fast-switching valve, $\mathrm{E}$ is air mass flow sensor, F is PC with Matlab/Bronkhorst FlowPlot software and $\mathrm{G}$ is $\mathrm{CX}$ controller with modules for pressure sensor and PWM modulation. The CX controller communicates with the PC via LAN network while mass flow sensor data is gathered on the PC via RS-232.

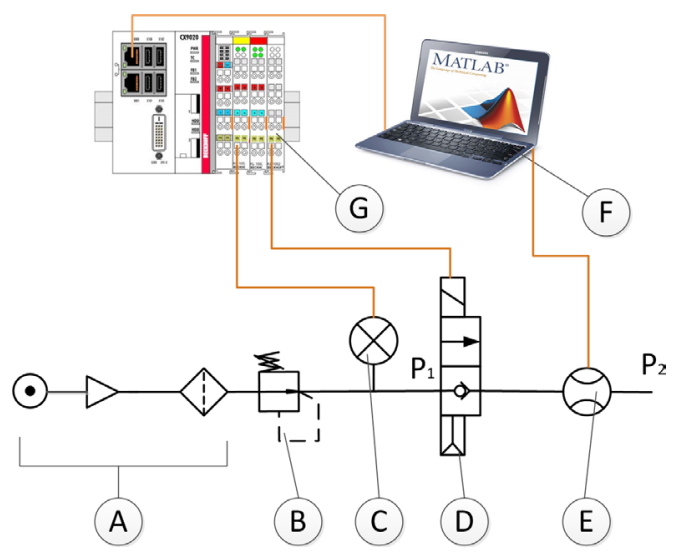

Fig. 2. Schematic diagram of the experimental setup

The pressure sensor, the fast-switching valve and the air mass flow sensor are connected via piping with an internal diameter of $4 \mathrm{~mm}$. To avoid air turbulence, 
the components must be mounted $100 \mathrm{~mm}$ apart, as shown on the experimental setup photography in Fig. 3.

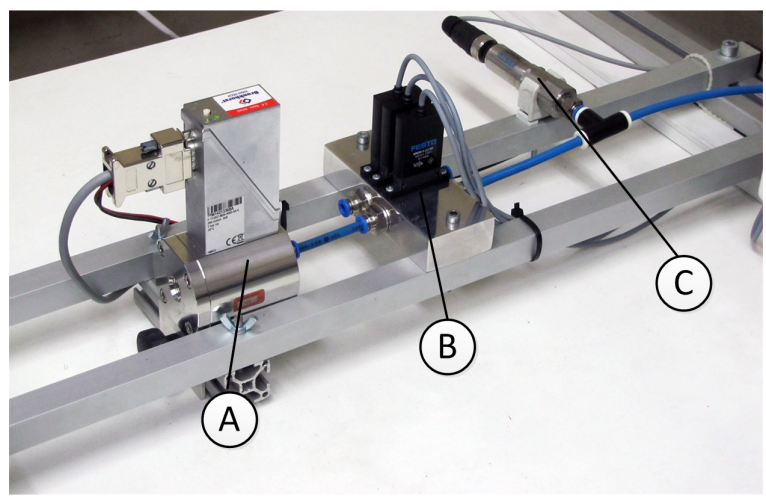

Fig. 3. Photograph of experimental setup main pneumatic components connected: A is air mass flow sensor, B fast-switching valve, and $C$ pressure sensor

The most important part of the experimental setup is the air mass flow sensor F-112AC by Bronkhorst. Sensor's measuring range in normal litres per minute is $\Phi_{V n}=1.4 \mathrm{Nl} / \mathrm{min}$ to $200 \mathrm{Nl} / \mathrm{min}$ with an accuracy of $0.5 \%$ of measured value plus $0.1 \%$ of full-scale [24]. Because of the sensor used and a relatively high PWM frequency, there is no need for special measurement equipment due to pressure pulsation [25]. The average volume flow of pulsation air flow can be measured with thermal anemometers if certain rules are taken into account [26]. First there must be no backflow. Since the inlet pressure is always higher at the valve outlet and there is no nozzle at the F-112AC outlet port, the backflow should not occur. $\mathrm{F}-112 \mathrm{AC}$ has two combined windings for heating and temperature measurement mounted on the capillary tube bypass [24]. The mass of the capillary tube with winding and housing, where the temperature drop is measured, is much greater than in hot-wire sensors. Air flow pulses with high frequency are damped since the mass temperature cannot change with same frequency. To get the average value of the air flow, the FlowPlot acquisition software sensor's exponential smoothing filter was set to slow the response [27]. The response time of $\mathrm{F}-112 \mathrm{AC} t_{63 \%}$ is 2 to 4 seconds, therefore the measurement for every pulse width will be at a minimum 10 seconds to achieve accurate measurement.

The tested valve, MHJ10-MF, is the fastest switching valve from Festo with the following specifications: nominal flow rate of $\Phi_{V}=100 \mathrm{l} / \mathrm{min}$, response time for opening $t_{\text {on }}=0.7 \mathrm{~ms}$, closing time $t_{\text {off }}=0.5 \mathrm{~ms}$ at pressure difference $\Delta P=0.1 \mathrm{bar}$, and $t_{\text {on }}=0.9 \mathrm{~ms}$, closing time $t_{\text {off }}=0.4 \mathrm{~ms}$ at $\Delta P=6 \mathrm{bar}$ [28]. The opening time, $t_{o n}$, increases and the closing time, $t_{\text {off }}$, decreases with the increase of the pressure difference due to the internal structure of the valve. The valve is normally closed due to pressure forces acting on the spool. The increased pressure difference increases the necessary electromagnetic force to open the valve and also closes the valve more rapidly. The internal structure schematics of the fast-switching pneumatic valve is presented in Fig. 4, where A is the solenoid, $\mathrm{B}$ is the air gaps that enable air pressure to close the valve, $\mathrm{C}$ is the metallic control spool, D is the valve inlet, $\mathrm{E}$ is the metering edge and $\mathrm{F}$ is the valve outlet.

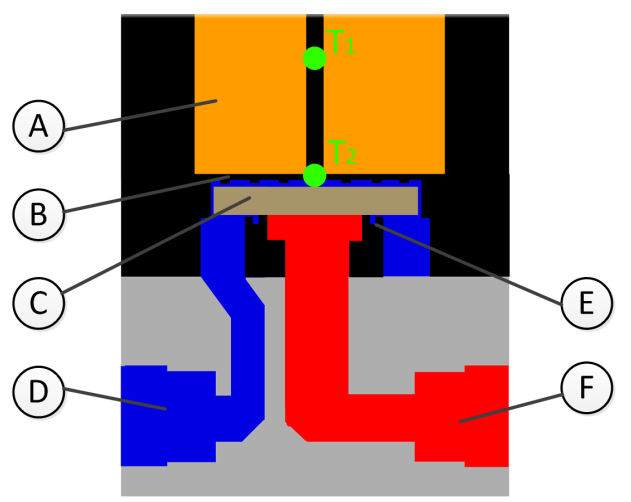

Fig. 4. Schematics of the fast switching valve internal components

$T_{1}$ and $T_{2}$ are positions of holes made on the valve housing $1.6 \mathrm{~mm}$ deep where we measured temperature during continuous excitation with PWM signal of $250 \mathrm{~Hz}$ and $50 \%$ duty cycle.

The pressure difference is set with the help of the pressure regulator and the pressure sensor positioned before the valve. Measurement uncertainty is calculated using the sensor and an A/D converter with specifications shown in Table 2.

Table 2. Measurement uncertainty

\begin{tabular}{|c|c|c|c|}
\hline \multicolumn{2}{|c|}{ Measurement element } & Uncertainty & Uncertainty [\% FS] \\
\hline \multirow{6}{*}{$\Delta P$} & \multirow{3}{*}{$\begin{array}{l}\text { Pressure sensor } \\
\text { SDET-22T }\end{array}$} & Repeatability & 0.25 \\
\hline & & Linearity & 0.4 \\
\hline & & Temperature & 0.15 \\
\hline & \multirow{2}{*}{$\begin{array}{l}\text { A/D converter } \\
\text { EL3104 }\end{array}$} & Repeatability & 0.3 \\
\hline & & Res. 16 bit & 0.00385 \\
\hline & $\begin{array}{c}\text { Pressure } \\
\text { measurement }\end{array}$ & $\begin{array}{c}\text { Combined } \\
\text { Uncertainty }\end{array}$ & 0.62916 \\
\hline \multirow{2}{*}{$\Phi_{V}$} & $\begin{array}{c}\text { Volume flow } \\
\text { sensor F-112AC }\end{array}$ & Repeatability & $\begin{array}{c}0.5 \% \text { measured } \\
\text { value }+0.1 \% \mathrm{FS}\end{array}$ \\
\hline & $\begin{array}{l}\text { Volume flow } \\
\text { measurement }\end{array}$ & $\begin{array}{l}\text { Combined } \\
\text { Uncertainty }\end{array}$ & $\begin{array}{c}0.5 \% \text { M.V. value } \\
+0.1 \% \text { FS }\end{array}$ \\
\hline$T$ & EasyCal 315 & Accuracy & $\pm 1.1^{\circ} \mathrm{C}$ \\
\hline
\end{tabular}


From the calculation we can conclude with $95 \%$ certainty that the measured pressure difference $\Delta P$ is in the range of \pm 0.0503 bar and volume flow $\Phi_{V n}$ is in the range from $\pm 0.207 \mathrm{Nl} / \mathrm{min}$ at flowrate $1.4 \mathrm{Nl} / \mathrm{min}$ to $\pm 1.2 \mathrm{Nl} / \mathrm{min}$ at flowrate $200 \mathrm{Nl} / \mathrm{min}$.

\subsection{Experimental Results}

All gathered data is available in Matlab data matrices for further analysis. The pulse width, $t_{\text {pulse }[\%]}[\%]$, was converted to time, $t_{\text {pulse }}[\mathrm{ms}]$ for better compatibility between frequencies. Fig. 5 presents the results for the measured flow at $\Delta P=6$ bar, Fig. 6 for $\Delta P=3$ bar and Fig. 7 for $\Delta P=0.1$ bar.

At the pressure difference of $\Delta P=6$ bar, the relation between pulse width and flow is almost linear. The maximum flow is reached at different pulse width as a function of PWM period and is defined by the PWM frequency period. Therefore the maximum flow for $f_{P W M}=200 \mathrm{~Hz}$ is reached with pulse a width around $t_{\text {pulse }}=5 \mathrm{~ms}$, for $f_{P W M}=250 \mathrm{~Hz}$ in $4 \mathrm{~ms}$ and $f_{P W M}=300 \mathrm{~Hz}$ in $3.33 \mathrm{~ms}$.

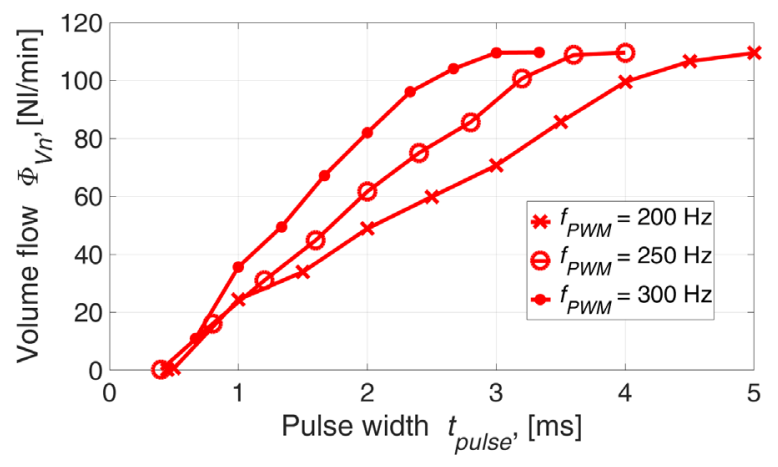

Fig. 5. Comparison of test results for pressure difference $\Delta P=6$ bar and different $P W M$ frequencies

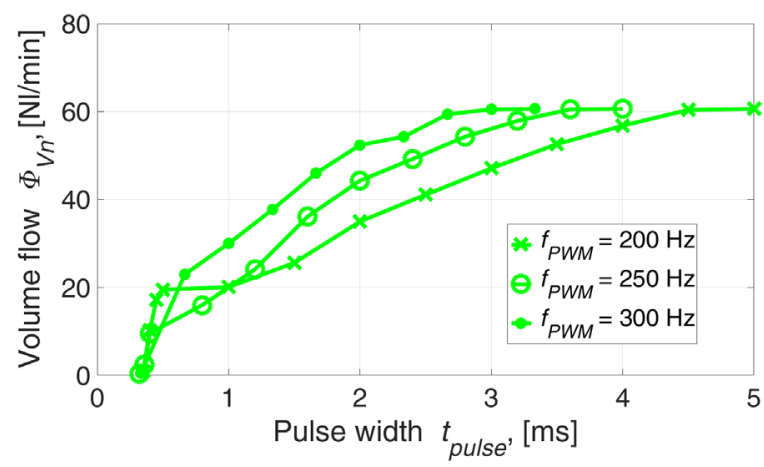

Fig. 6. Comparison of test results for the pressure difference $\Delta P=3$ bar and different $P W M$ frequencies
As the pressure difference drops, the relationship between valve control signal pulse widths and volume flow becomes nonlinear. This is most prominent at lower frequencies when the valve starts to open. The volume flow has a steeper slope in the beginning and later becomes flatter.

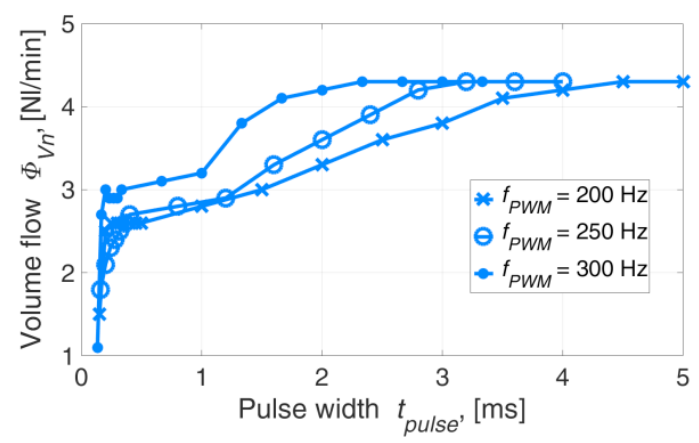

Fig. 7. Comparison of test results for the pressure difference $\Delta P=0.1$ bar and different $P W M$ frequencies

At the lowest pressure difference, the flow increases almost vertically when the valve starts to open. Also at $f_{P W M}=200 \mathrm{~Hz}$ the relation between the pulse width and the volume flow is not linear even at the initial steep response.

The minimum pulse $t_{\min }[\mathrm{ms}]$ increases from 0.14 $\mathrm{ms}$ to $0.4 \mathrm{~ms}$ and increases with pressure difference. In Fig. 8, the comparison of all three frequencies and different pressure differences is given. There is a slight difference between frequencies in Fig. 8. Since the resolution of $t_{\min \%}$ is $0.1 \%$ and the measurement accuracy of the pulse width is $\pm 0.01 \mathrm{~ms}$. The extended normal distribution of measurements is $\pm 0.00944 \mathrm{~ms}$. which means, that differences between all the three frequencies is within $95 \%$ certainty (Table 1) of the measurement error domain and is not a function of different PWM frequencies.

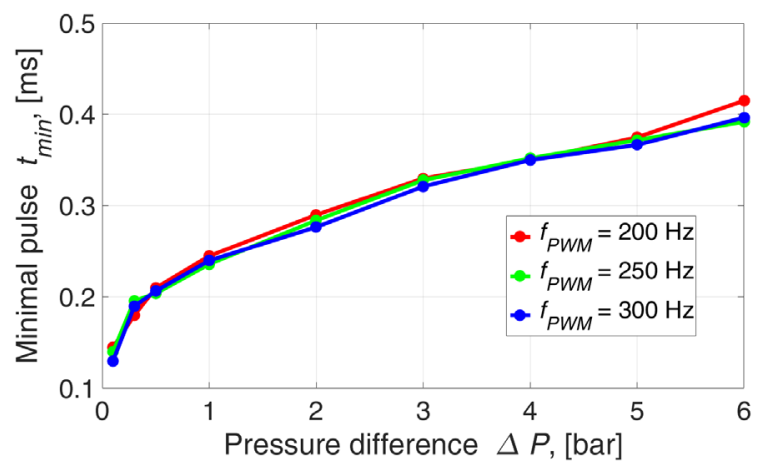

Fig. 8. Minimum PWM pulse tmin as a function of $\Delta P$ 
The widest pulse that still has an effect on the volume flow characteristics $t_{\max }[\mathrm{ms}]$ is the function of frequency because the frequency determines the period of the pulse. Experimental results of the maximum pulse width are presented in Fig. 9.

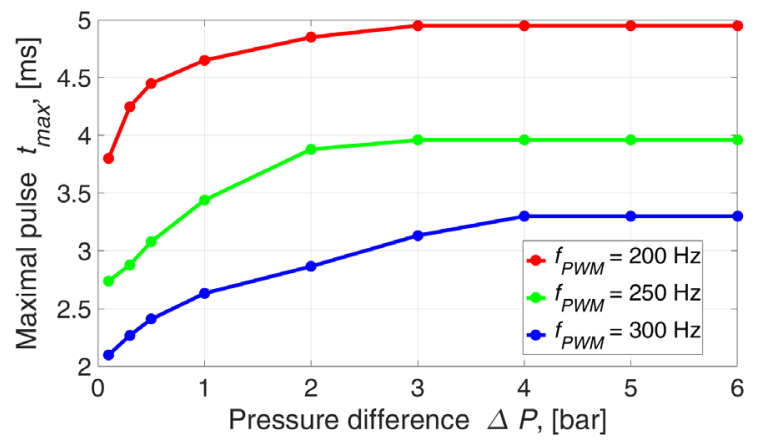

Fig. 9. Maximum $P W M$ pulse tmax as a function of $\Delta P$

To choose the best of three tested frequencies, the comparison of flow characteristics and pulse widths for three pressure differences is necessary.

Presented data shows that there are differences between frequencies but it is hard to see clearly which one has the smoothest transition for lower pressure differences. To choose the optimal PWM frequency, all the data is normalized. This is done by converting the mass air flow data to volume flow as percentage at a given pressure difference. Also pulse widths are converted from milliseconds to percentages. In Fig. 10 , the comparison of all three different frequencies at three differential pressures is shown.

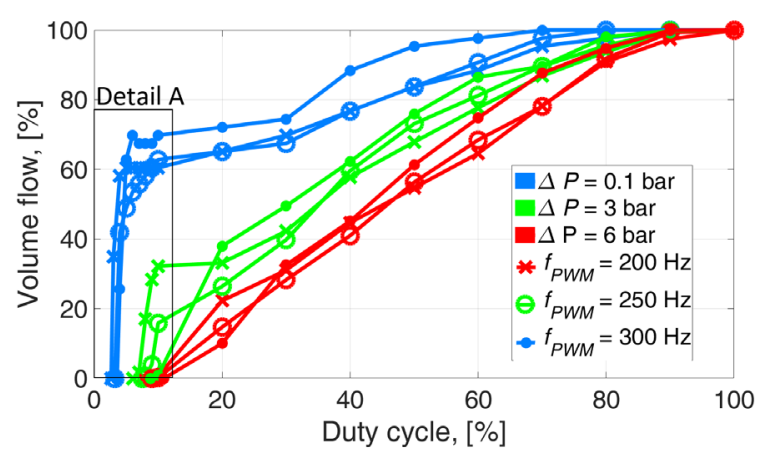

Fig. 10. Comparison of normalized data for all three PWM frequencies and three pressure differences

It is obvious that at lower pressure differences the flow through the valve has a very steep curve which normalizes at about $10 \%$ or $0.5 \mathrm{~ms}$ of the pulse width and then progresses relatively linearly. At higher pressure differences, the characteristics are almost linear. To achieve the best control of the volume flow through the valve using fast pneumatic valves and PWM, it is crucial to have smooth characteristics at lower pressure differences as well. The smoothest transition from the closed valve to the first $10 \%$ $(0.5 \mathrm{~ms})$ of the PWM duty cycle was found for the frequency $f_{P W M}=250 \mathrm{~Hz}$ as shown in detail A of Figs. 10 in 11. Higher frequencies decrease the life span and the control resolution of the valve.

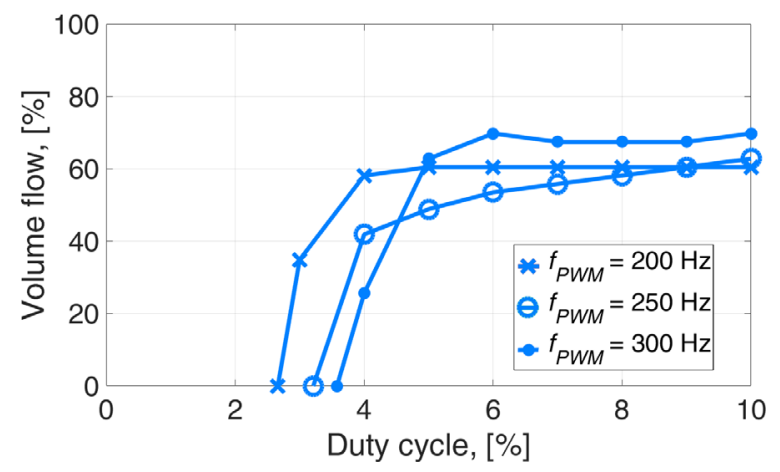

Fig. 11. Detail A of Fig. 10: PWM frequency comparison for

$$
\Delta P=0.1 \text { bar }
$$

Experimental results show that with faster response of fast-switching valves higher PWM frequencies can be used. The maximum tested frequency so far was $100 \mathrm{~Hz}$. With even higher PWM frequencies we get further away from natural frequencies of pneumatic components and achieve more stable control and faster responses.

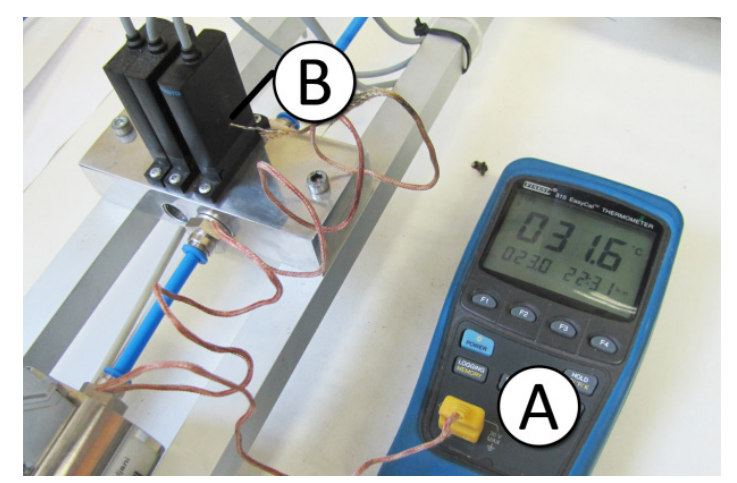

Fig. 12. Temperature measurement of $T_{1}$ during temperature testing of Festo valve (A is a digital thermometer EasyCal 315, and $B$ Festo valve with thermocouple inserted in position $T_{1}$

Measurement of the temperatures $T_{1}$ (measured in a hole made in the valve housing between 2 solenoids) and $T_{2}$ (measured in a hole made on the bottom of two solenoids) was made for duration of 8 hours using a digital thermometer EasyCal 315 with thermocouple. The ambient air temperature was 24.2 
${ }^{\circ} \mathrm{C}$. The measurement was taken automatically every minute. Measurement during temperature $T_{1}$ test is shown on Fig. 12. Fig. 13 shows temperatures $T_{1}$ and $T_{2}$ during the 8 hour testing of the Festo Valve with the PWM frequency $f_{P W M}=300 \mathrm{~Hz}$ and duty cycle of $50 \%$. The solenoid temperature $T_{1}$ becomes stable at approximately $70{ }^{\circ} \mathrm{C}$ and $T_{2}$ at $28{ }^{\circ} \mathrm{C}$. Both temperatures are below maximum temperature defined by the manufacturer $\left(T_{1 \max }=155^{\circ} \mathrm{C}\right.$ and $T_{2 \max }$ $=60{ }^{\circ} \mathrm{C}$ ) [28]. The temperature $T_{1}$ increases due to the heating of the solenoid and heat is mainly transferred through valve housing into ambient air. $T_{2}$ is also heated with solenoid but the majority of the heat is transferred via constant air flow through the valve.

Valve temperature $T_{1}$ and $T_{2}$ achieves its maximum value after approximately 10 minutes as shown in Fig 14.

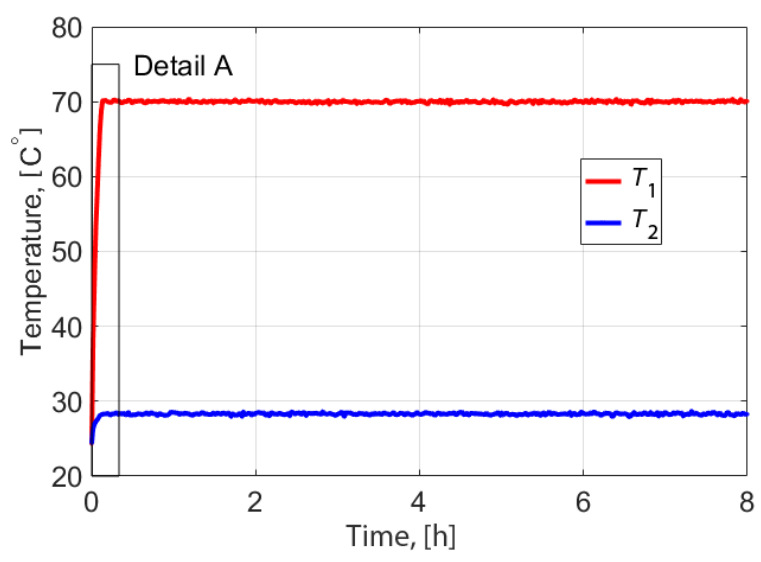

Fig. 13. Change of valve temperature $T_{1}$ and $T_{2}$

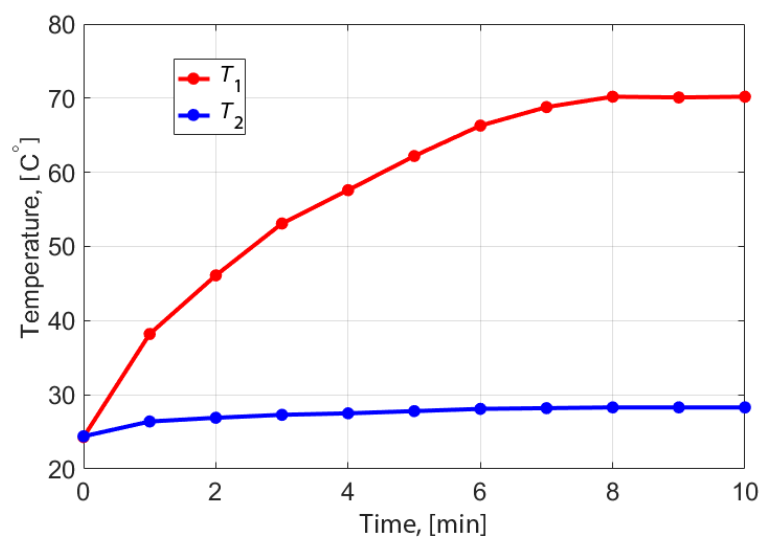

Fig. 14. Detail A of Fig. 13 of valve temperature for the first 10 minutes

\section{CONCLUSIONS}

In this paper, we presented an experimental analysis of flow characteristics of fast-switching valve controlled via different PWM signals. We tested the effects of different frequencies and pulse widths of PWM signals at various pressure differences on volume flow through the fast-switching valve. Experiments clearly show that minimal pulse width needed to open the valve increases with the incensement of pressure difference from $0.14 \mathrm{~ms}$ to $0.4 \mathrm{~ms}$. This is the result of air pressure forcing the spool into the closed position and therefore electromagnetic force needs more time to open the valve.

At lower pressure differences $(\Delta P<1$ bar), when the valve is just starting to open, the volume flow increases almost vertically. This is due to the unstable dynamic equilibrium of low pressure forces that are controlled by stronger pulses of electromagnetic forces.

At pressure differences higher than 1 bar, the correlation between PWM duty cycle and volume flow becomes almost linear and does not have initial vertical responses.

The frequency $f_{P W M}=250 \mathrm{~Hz}$ is the most stable and has the most continuous transition at lower pressures. It is 5 times higher than the natural frequency of standard pneumatic components. Considering the calculation that the valve lifespan is 5 billion of switching cycles, the valve could work continuously for 243 days.

Experimental results will be used to develop a new control algorithm that will be able to continuously control volume flow via PWM control signals and fast-switching pneumatic valves. To achieve short response time and linear volume flow control, the smart algorithm must be based on the following conditions:

1. The pressure difference must be measured or calculated so that the control algorithm can calculate the best solution for the given system state.

2. The control algorithm must define the minimal PWM pulse as a function of the pressure difference. This way the shortest response time that mimics the characteristics of pneumatic servo valve can be achieved.

3. Depending on the pressure difference and the desired volume flow, the pulse width must be calculated.

4. The PWM frequency will be $250 \mathrm{~Hz}$.

The new control algorithm will be based on mathematically modelled experimental data to accurately describe the correlation between the pulse width and the desired valve opening. Valve temperature measurement showed that the temperature does not exceed maximum allowed valve temperature 
when exciting the valve with $\mathrm{PWM} f_{P W M}=300 \mathrm{~Hz}$. Therefore, we have proved that the PWM frequency of up to $f_{P W M}=300 \mathrm{~Hz}$ can be used without additional cooling. Experimental data will also be used to validate a new Lumped Parameter Model simulation model.

\section{REFERENCES}

[1] Keski-Honkola, P., Pietola M. (2008). Generating Vibration with Artificial Muscles. Ventil, vol. 14, no. 6, p. 558-564.

[2] Zhu, X., Tao, G., Yao, B., Cao, J. (2009). Adaptive robust posture control of a parallel manipulator driven by pneumatic muscles with redundancy. IEEE Transactions on Mechatronics, vol. 17, no. 3, p. 576-588, DOI:10.1109/TMECH.2008.2000825.

[3] Leephakpreeda, T. (2011). Fuzzy logic based PWM control and neural controlled-variable estimation of pneumatic artificial muscle actuators. Expert System with Application, vol. 38, no. 6, p. 7837-7850, Dol:10.1016/j.eswa.2010.12.120.

[4] Chandrapal, M., Chen, X., Wang, W., Hann, C. (2012). Nonparametric control algorithms for a pneumatic artificial muscle. Expert Systems with Applications, vol. 39, no. 10, p. 8636-8644, DOI:10.1016/j.eswa.2012.01.190.

[5] Giurgiutiu, V., Lyshevski, S.E. (2009). Microcontrollers for sensing, actuation and process control. Giurgiutiu, V., Lyshevski, S.E. (eds.) Micromechatronics: Modeling Analysis, and Design with MATLAB, p. 727-884, CRC Press, Boca Raton, DOI:10.1201/b15830-13.

[6] Liptak, B.G. (1999). Instrument Engineers' Handbook: Process measurement and analysis, CRC Press, Boca Raton.

[7] Belforte, G., Mauro, S., and Mattiazzo, G. (2004). A method for increasing the dynamic performance of pneumatic servo systems with digital valves. Mechatronics, vol. 14, no. 10, p. 1105-1120, Dol:10.1016/j.mechatronics.2004.06.006.

[8] Ying, C., Jia-fan, Z., Can-jun, Y., Bin, N. (2007). Design and hybrid control of the pneumatic force-feedback systems for Arm-Exoskeleton by using on/off valve. Mechatronics, vol. 17, no. 6, p. 325-335, DOI:10.1016/j.mechatronics.2007.04.001.

[9] Topçu, E.E., Yüksel, I., Kamiş, Z. (2006). Development of electro-pneumatic fast switching valve and investigation of its characteristics. Mechatronics, vol. 16, no. 6, p. 365-378, D0l:10.1016/j.mechatronics.2006.01.005.

[10] Ahn, K., Yokota, S. (2005). Intelligent switching control of pneumatic actuator using on/off solenoid valves. Mechatronics, vol. 15, no. 6, p. 683-702, D0l:10.1016/j. mechatronics.2005.01.001.

[11] Taghizadeh, M., Ghaffari, A., Najafi, F. (2009). Improving dynamic performances of PWM-driven servo-pneumatic systems via a novel pneumatic circuit. ISA Transactions, vol. 48, no. 4, p. 512-518, Dol:10.1016/j.isatra.2009.05.001.

[12] Taghizadeh, M., Ghaffari, A., Najafi, F. (2009). Modeling and identification of a solenoid valve for PWM control applications. Comptes Rendus Mécanique, vol. 337, no. 3, p. 131-140, DOl:10.1016/j.crme.2009.03.009.

[13] Najjari, B., Barakati, S.M., Mohammadi, A., Futohi, M.J., Bostanian, M. (2014). Position control of an electro-pneumatic system based on PWM technique and FLC. ISA Transations, vol. 53, no. 2, p. 647-657, Dol:10.1016/j.isatra.2013.12.023.
[14] Wang, Q., Yang, F., Yang, Q., Chen, J., Guan, H. (2011). Experimental analysis of new high-speed powerful digital solenoid valves. Energy Conversion and Management, vol. 52, no. 5, p. 2309-2313, DOI:10.1016/j.enconman.2010.12.032.

[15] Xiang, Z., Liu, H., Guoliang, T. (2010). Development and investigation of high-speed pneumatic jet valves by lumped

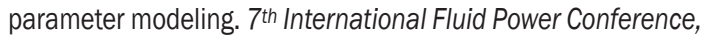
Workshop proceedings, p. 261-271.

[16] Zhang, J., Lv, C., Yue, X., Li, Y., Yuan, Y. (2014). Study on a linear relationship between limited pressure difference and coil current of on/off valve and its influential factors. ISA Transactions, vol. 53, no. 1, p. 150-161, Dol:10.1016/j. isatra.2013.09.008.

[17] ISO 6358-1:2013. (2013). Determination of flow-rate characteristics of components using compressible fluids Part 1: General rules and test methods for steady-state flow. International Organization for Standardization, Geneva.

[18] S.-N. Yun, D.-W. Yun, H.-H. Kim (2010). Flow characteristics of the piezoelectric driven pneumatic valve for grain sorter. $7^{\text {th }}$ International Fluid Power Conference, Workshop proceedings, p. 273-283.

[19] Lovrec, D. Kastrevc, M. (2011). Modelling and simulating a controlled press-brake supply system. International Journal of Simulation Modelling, vol. 10, no. 3, p. 133-144, D0l:10.2507/ IJSIMM10(3)3.184.

[20] Lotz, M., Bruhm, H., Czinki, A. (2014). An new force control strategy improving the force control capabilities of standard industrial robots. Journal of Mechanics Engineering and Automation, vol. 4, p. 276-283.

[21] Yuan, L.-W., Li, S.-M., Peng, B, Chen, Y.-M. (2015). Study on failure process of tailing dams based on particle flow theories. International Journal of Simulation Modelling, vol. 14, no. 4, p. 658-668, DOI:10.2507/IJSIMM14(4)8.322.

[22] Cuesta, E., Mantaras, D.A., Luque, P. Alvarez, B.J. (2015). Dynamic deformations in coordinate measuring arms using virtual simulation. International Journal of Simulation Modelling, vol. 14, no. 4, p. 609-620, D0l:10.2507/ IJSIMM14(4)4.311.

[23] Karadžić, U., Bulatović, V., Bergant, A. (2014). Valve-induced water hammer and column separation in a pipeline apparatus. Strojniški vestnik - Journal of Mechanical Engineering, vol. 60, no. 11, p. 742-754, D0I:10.5545/sv-jme.2014.1882.

[24] Bronkhorst (2014). Instruction manual EL-FLOW Base series Mass Flow Sensors. Bronkhorst High - Tech B.V., p. 8-10.

[25] Berson, A., Blanc-Benon, P., Comte-Bellot, G., (2010). On the use of hot-wire anemometry in pulsating flows. A comment on 'A critical review on advanced velocity measurement techniques in pulsating flows'. Measurement Science and Technology, vol. 21, no. 12, p. 1-6, Dol:10.1088/09570233/21/12/128001.

[26] Bronkhorst (2016). Instruction manual: FlowPlot Software tool for monitoring FLOW-BUS parameter values and optimizing controller settings of digital instruments. Ruurlo, p. 14.

[27] Grabe, C., Bebber, D., Murrenhoff, H. (2012). Development of a method to evaluate CNG-injection valves. ASME/BATH 2015 Symposium on Fluid Power and Motion Control, Chicago.

[28] FESTO (2012). Solenoid valves MHJ - fast-switching valves technical data, Festo. 